AperTO - Archivio Istituzionale Open Access dell'Università di Torino

\title{
An analytical approach for the non-invasive selection of consolidants in rubber artworks
}

\section{This is the author's manuscript}

Original Citation:

Availability:

This version is available http://hdl.handle.net/2318/1578004

since 2016-06-30T14:14:36Z

Published version:

DOI:10.1007/s00216-016-9673-y

Terms of use:

Open Access

Anyone can freely access the full text of works made available as "Open Access". Works made available under a Creative Commons license can be used according to the terms and conditions of said license. Use of all other works requires consent of the right holder (author or publisher) if not exempted from copyright protection by the applicable law. 


\title{
An analytical approach for the non-invasive selection of consolidants in rubber artworks
}

\author{
Marcello Manfredi ${ }^{1,2,{ }^{*}}$, Elettra Barberis ${ }^{1,2}$, Antonio Rava ${ }^{3}$, Tommaso Poli ${ }^{4}$, Oscar Chiantore ${ }^{4}$, Emilio Marengo ${ }^{1}$ \\ ${ }^{1}$ Dipartimento di Scienze e Innovazione Tecnologica, Università del Piemonte Orientale, viale Teresa Michel 11, \\ Alessandria, Italy \\ ${ }^{2}$ ISALIT S.r.1., Via G. Bovio 6, Novara, NO, Italy \\ ${ }^{3}$ Centro Conservazione e Restauro La Venaria Reale, via XX Settembre 18, Venaria Reale, TO, Italy \\ ${ }^{4}$ Università degli Studi di Torino, Dipartimento di Chimica, Via P. Giuria, 7, Torino, Italy \\ ${ }^{*}$ Corresponding author: marcello.manfredi@uniupo.it; +39 3334722270
}

\begin{abstract}
The effectiveness of five polymeric materials for the long-term conservation and restoration of rubber artworks were evaluated by accelerated photo-oxidative degradation studies. Two different ethylene vinyl-acetate resins, generally used in industry and uncommon in conservation field, a new waterbased polyurethane and two ethylene butyl-acrylate resins were assessed for the consolidation of rubber. By monitoring their degradation along time with LED imaging coupled to statistics and Fourier Transform Infrared Spectroscopy (FTIR), the polymeric materials with the best properties that ensure the protection and security of the artwork were identified. The degradation was performed in solar box simulating the light exposure in a museum, under controlled temperature at no more than $35^{\circ} \mathrm{C}$ in order to exclude the thermal effects that could influence the ageing of polymers. The mechanical stress of the treated samples was also investigated. The spectroscopic analyses, the chromatic changes study and the mechanical degradation were used as indicators of the consolidants stability, allowing the evaluation of the materials selected for the consolidation and conservation of rubber. The ethylene-vinyl acetate copolymers resulted the most stable and suitable for the conservation of rubber artworks. Lastly, the conservation treatment identified in this research was employed for the restoration of the contemporary artwork "Presagi di Birnam" made with bicycle inner tubes by the artist Carol Rama.
\end{abstract}

Keywords: Non-invasive methods, Polymers, Rubber Restoration, Consolidants, LED Imaging 


\section{Introduction}

The modern and contemporary art collections represent the artistic innovation that has gone through the last century: the number of these artifacts is destined to grow over time. At the same time, there is a lack of knowledge about the conservation and restoration of these complex artworks that often are degrading faster than expected: protocols and protection solutions able to increase their expected lifetime would allow to improve the value of our cultural heritage and to preserve them to the future generations. It is very important and related to the professional ethic that the restoration and the investigation of the conservation status do not jeopardize the object both in its material and immaterial existence: for this reasons there is an increasing interest in the development and study of new safe and sustainable restoration materials.

Contemporary art includes the use of synthetic materials, which are not designed for a long life. During the last century, artists have used a wide variety of materials and their combinations (like organic and non-organic supports, binders, pigments, etc., plus modern ones - elastomers, polymers, fiberglass, synthetic and biodegradable materials, etc...), which today are considered an expression of the artwork itself.

The deterioration of many thousands of artworks constituted by polymers, or polymer-containing objects, is now becoming evident and research questions regarding the durability of contemporary objects need to be addressed [1,2]. For example, the UE funded POPART project was aimed at investigating the possibility of using non-invasive analytical tools for diagnostics on plastics artworks in museum collection [3]. Moreover, non-invasive methods have been widely employed for the characterization and study of artworks materials and degradation processes [4-7].

The conservation of these artifacts constituted by several types of modern and not traditional materials is not always carried out so far in a scientific manner. Moreover, their degradation results in different effects and problems that ranges from superficial dirt, abrasion, color changes, scratches, shrinking, etc., that are related to the composition of the artwork and to its conservation state. Polymeric materials can be successfully used to reduce the ageing caused by thermal and photo-oxidative phenomena, to outdoor exposure, to replace missing pieces, to consolidate and to protect the artworks. Although polymers have been widely employed and studied for the consolidations of artefacts [8-11], some commercial products are not always suitable for the application to modern and not traditional synthetic materials and have never been specifically tested.

The production of synthetic rubber at the beginning of the twentieth century has led several artists such as Pablo Picasso, Marcel Duchamp, Richard Serra, Eva Hesse, Robert Rauschenberg and Piero Gilardi to experiment the use of this material in various ways.

Oxygen, ozone, heat and light exposure have a deterioration action on rubber and represent the most dangerous problems for this material. Along the time, rubber absorption of oxygen promotes structural changes and depolymerization phenomena: rubber becomes sticky or dry until the complete loss of its original elasticity. These degradation processes are catalyzed by constant exposure of the material to UV and heat. Furthermore, the reaction between the vulcanization sulfur and oxygen may develop sulfuric acid and accelerate the processes of rubber alteration, creating fractures and structural changes. Depending on the conditions of rubber manufacture, the phenomena is manifested by the softening or the crumbling of the materials, or by exudation, loss of elasticity and flexibility, or by the hardening and embrittlement that lead to the formation of fractures or surface deformations. Once degradation becomes evident, it is often too late to save rubber material [12]. If not controlled, the decay becomes exponential and can lead to the complete loss of the material. For these reasons conservators and scientists should pay special attentions to rubber museum objects and should monitor continuously their state of conservation [13-15]. 
Infrared spectroscopy is widely used for polymer identification and ATR-FTIR shows excellent results in polymer characterization [1]. Accelerated aging experiments have already been employed in several researches in order to study the materials surface deterioration [16-19]. By increasing the understanding of polymer properties valuable improvements of the treatments and of the materials employed can be obtained.

Polymers are used for many purposes in the conservation of objects (as consolidants, adhesives, coatings, moulding, etc...), but normally the choice is restricted to the products commercially available, which are typically present in many versions. The effectiveness of polymeric materials for the long-term conservation and restoration of artworks, for reducing and blocking the materials degradation, for increasing their resistance to environmental factors as well as for replacing missing pieces, must be therefore evaluated by degradation studies.

While there are many studies on the degradation of restoration commercial products, there is no comprehensive study on the evaluation of materials suitable for the consolidation and conservation of rubber. The purpose of this research was to identify, study and test the best conservative treatments to be employed for the restoration of the contemporary artwork "Presagi di Birnam" (Figure 1), made with bicycle tires by the artist Carol Rama (Turin, Italy, 1918-2015). New potential polymeric consolidants were selected for the artwork treatment and the validity of these products was tested with accelerated ageing. Photo-oxidative degradation is the most dangerous and uncontrollable problem for rubber, and the artificial ageing was performed in a solar box simulating the light exposure in a museum. The degradation was monitored along time using LED imaging [20-22] and FTIR spectroscopy in order to identify the polymeric materials with the best properties that ensure the long-term protection and security of the artwork

\section{Materials and Methods}

\section{Selection of the polymeric consolidants}

The consolidating materials must match the following properties to be employed for rubber restoration treatments: (i) present good adhesion to the substrate; (ii) be chemically stable; (iii) not induce chemical or physical changes after the rubber treatments; (iv) be easily reversible and (v) flexible [23]. A recent conservation research based on the study of new materials for the restoration and conservation of a design object containing rubber parts has been presented [24, 25]. In this work, copolymers of ethylene-vinylacetate (EVA) and of ethylene-butylacrylate (EBA) and a polyurethane $(\mathrm{PU})$ in aqueous dispersion were investigated for the consolidation and protection of natural rubber.

The use of EVA copolymers for the conservation of artworks started in 1970 when Gustav Berger presented his first research on the use of a synthetic conservation adhesive, the BEVA 371, based on two different ethylene-vinylacetate copolymers, two tackifiers, a wax and a solvent carrier. The presence of EVA copolymers increases the structural strength of waxes because of its greater elasticity and rigidity [26-29]. Although several researches have been published on its long-term stability, some conservators, after using the material, have reservations about its removability and yellowing over time [30-36].

Nowadays the ethylene-vinyl acetate copolymers are widely used for many purposes [37]. The weight percent of vinyl acetate (VA), which ranges generally between $5 \%$ and $50 \%$, determines the flexibility of the compound. Flexibility, resilience, toughness and transparency increase with increasing vinyl acetate content. Upon the increase in VA content, the copolymer becomes softer, parallel to the decrease in crystallinity [38]. Two different ethylene vinyl-acetate resins, generally used in industry and uncommon in the conservation field, were tested in this work: EVATANE® 42-60 (EVA4260) and EVATANE® 40-55 (EVA4055) from Arkema. The two products were selected because of their high content of Vinyl Acetate VA (41-44\% for EVA4260 and 38-41\% for EVA4055), the absence of additives and their availability on the market. 
The most important study conducted on consolidating adhesives used in restoration is from the Canadian Conservation Institute. This research showed good properties especially in EVA and in ethylene- acrylate copolymers and suggested the necessity of a closer examination of these classes [39]. Among the different copolymeric structures which can be found on the market we focused on two ethylene-butylacrylate (EBA) copolymers from Arkema (France), named Lotryl 35BA40® (EBA40) and Lotryl 35BA320® (EBA320); they have the same BA content (35\%) but a different molecular weight as indicated by the melt index, which is higher in the EBA 320. EBA40, on the other hand, has a better tensile strength and elongation at break than EBA320. The high percentage of Butyl Acrylate BA (35\%) introduced into the polymer molecules keeps the products flexibile and this would fit the necessities of the rubber treatment.

Polyurethanes (PU) are widely used for the restoration of polyurethane foams and in a recent study a PU (Impranil DLV/1®, Bayer, Germany) was employed for the restoration of rubber [24, 25]. In this research a new, more flexible aqueous dispersion of PU, Impranil DLU® from Bayer, was assessed for the consolidation of rubber and compared with the other polymers. In Table 1 the selected polymeric consolidants are listed with their nominal compositions and some characterization data given from the producers.

\section{Sample preparation and rubber treatments}

The vinyl acetate and butyl acrylate polymers were dissolved in 5\% cyclohexane while the polyurethane was used as aqueous dispersion. Five rubber samples $(2 \times 4 \mathrm{~cm}$ of size), in the past belonging to the artwork "Presagi di Birnam" and obtained from the artist Carol Rama, were treated with the selected materials while one sample was left untreated and used as control. The rubber was cleaned with demineralized water before the application of the consolidant, which was spread on it. The restorer accurately and uniformly distributed the consolidants on the samples. The samples were dried in laboratory under controlled temperature and humidity $\left(23^{\circ} \mathrm{C}\right.$ and $\left.50 \% \mathrm{RH}\right)$ for 48 hours and then analyzed.

\section{Sample analysis}

ATR-FTIR

Fourier transform infrared spectral analysis of the samples treated with the consolidants was conducted using ATR-FTIR. All the spectra were obtained using an Agilent 4100 Exoscan FTIR portable spectrometer (Agilent Technologies, Santa Clara, CA, USA). Sample spectra were obtained in absorption mode over a wavelength of $650 \mathrm{~cm}^{-1}$ to $4000 \mathrm{~cm}^{-1}$ at 32 scans per sample and a resolution of $4 \mathrm{~cm}^{-1}$. Background readings of air were established prior to data collection. The background was subsequently subtracted from each spectrum before data treatment. Three infrared spectra of each sample were collected in different position and the average spectra were used for identification purposes.

\section{LED Multispectral Imaging Monitoring Technique}

In a previous work we developed a quantitative LED multispectral imaging method coupled to multivariate statistics for the automatic detection of degradation processes on cultural heritage surfaces, including their localization and identification, before their degradation effects may become visible to the human eye [20].

The method employed for this work follows a well-validated workflow and protocol based on Shewhart Control chart that reports the behavior of a property (the reflectance) along time. If the reflectance of the sample is statistically changed, the control chart recognized the area. The region of statistical control is described as a range of values that lay within a range of values of 3 times the standard deviation around the score of the significant principal component, which represents the spectra reflectance. This region corresponds to a confidence level of more than $99 \%$ and anomalous process behaviors can be identified when any point falls outside the $3 \sigma$ region ( $\mathrm{R}$ error is $<1 \%$ ). In this way, 
if a sample violates the natural correlation structure characterizing the data set, this sample will show anomalous score values that will be recognized on the control chart. A statistical significance level of $99 \%$, which is more conservative, was employed in order to avoid false positive and to get more confident results.

In this study we applied the method through the following steps:

a. Multispectral characterization of the surfaces: the characterization was accomplished by recording a set of replicated multispectral images (10 replicates) before the application of the accelerated artificial ageing.

b. Alignment of replicated multispectral images: the image cubes collected during different imaging sessions were accurately aligned pixel by pixel. The image alignment is very important in order to compare the same pixel before and after the degradation.

c. Principal component analysis (PCA) of the baseline data set: this step enabled the description of the initial conservation state of the samples by means of the relevant principal components (PCs). The relevant PCs take into account the systematic relationships present in the data and the multivariate control charts are calculated using their scores. For each pixel the upper (UCL) and lower (LCL) control limits are calculated (mean value of the score of each pixel plus three times its standard deviation for the UCL and minus three times its standard deviation for the LCL) within which the sample can be considered unchanged. The PCA was carried out on the set of replicated multispectral images (reflectance spectra) of the samples.

d. Conservation treatments monitoring: multispectral images of the samples treated with the different conservation substances have been acquired during the artificial ageing; they have been aligned to the initial images and then projected onto the principal component space previously obtained. This operation allows their comparison with the control limits calculated during the characterization step and the identification of the pixels that exceed the control limits.

A homemade portable multispectral imaging system was employed for the acquisition of multispectral images of the samples treated with different conservation treatments. The sample is actively illuminated by light-emitting diodes (LEDs) generating different spectral bands while a monochrome camera captures the reflected light. Two identical LED panels (Equipoise Imaging LLC, MD, USA), each consisting of 8 different LEDs (370, 444, 466, 598, 521, 600, 640 and $923 \mathrm{~nm}$ ) were employed. A CCD camera with an 8.3-megapixel Kodak CCD monochrome sensor array (ST8300M, Santa Barbara Instrument Group, CA, USA), 17.96 x 13.52, with 3326 x 2504 pixels, 5.4 x $5.4 \mu \mathrm{m}$ was employed for the images acquisition.

For the statistical analysis and all other computations the MATLAB software (The MathWorks, version R2013b) and the open source software ImageJ were used [41].

The result of the initial characterization is a model of the state of conservation of the samples before degradation. The outcome of the monitoring is a control chart composed of an image where each pixel represents the position of the same point of the sample. The pixels are pseudo-colored according to whether they represent a changed (out of control points) or an unchanged area. In this paper red pixels are the changed pixels while green pixels correspond to unchanged regions, or in control points.

\section{Artificial light ageing}

In order to identify the best restoration treatment to be employed for the conservation of rubber artworks, five rubber samples $(2 \times 4 \mathrm{~cm}$ of size) treated with the five selected treatments and one untreated control sample were subjected to artificial accelerated degradation for 400 hours in a solar box with a light exposure of $700 \mathrm{Watt} / \mathrm{m}^{2}$, simulating natural 
light exposure. The degradation was performed in a solar box under controlled temperature at no more than $35^{\circ} \mathrm{C}$ in order to avoid thermal effects of degradation. The samples were characterized and monitored during the accelerated degradation by using ATR-FT-IR and LED multispectral imaging. ATR-FT-IR was used to identify the formation/disappearance of chemical species in treated samples while the LED Multispectral Imaging technique was used mainly to detect reflectance/chromatic variation of the sample surface.

The LED multispectral imaging characterization was performed following the methods described in our previous work [20-22] and the samples were monitored after 155 and 400 hours. The samples were analyzed with ATR-FT-IR before ageing, after $31,155,227,330$ and 400 hours of ageing in solar box.

Mechanical ageing

The mechanical stress to which the bicycle inner tubes of the artwork are subject has been investigated by stretching longitudinally for $0.5 \mathrm{~cm}$ rectangular rubber samples having dimensions $2 \times 4 \mathrm{~cm}$ of size. The samples were fixed with steel nails to a wood support for 240 hours. Every 24 hours the samples were visually monitored in order to identify cracks and breakages. The analysis was performed on five different replicates for each treated sample and the control, and the average breaking time for each conservation treatment and for the controls was recorded.

\section{Results and discussion}

\section{Characterization of rubber samples and of conservation materials}

The rubber inner tubes used by the artist for the "Presagi di Birnam" artwork were analyzed by FT-IR and it turned out that the material was invariably polyisoprene 1,4-cis. This result is in agreement with industrial data on the materials and production of inflatable tires.

Figure 2a shows the infrared spectrum of a sample from one of the rubbers that constitute the artwork: the specific absorption bands for polyisoprene are the $\mathrm{C}-\mathrm{H}$ alkene deformation vibration at $1448 \mathrm{~cm}^{-1}\left(-\mathrm{CH}_{2}-\right.$ scissor vibration) and $1376 \mathrm{~cm}^{-1}\left(\mathrm{C}-\mathrm{CH}_{3}\right)$, and the $\mathrm{C}=\mathrm{C}-\mathrm{H}$ vibration at $834 \mathrm{~cm}^{-1}$. At $2959 \mathrm{~cm}^{-1}$ and $2851 \mathrm{~cm}^{-1}$ there are the $\mathrm{CH}_{3}$ asymmetric and symmetric stretchings are visible; at $2924 \mathrm{~cm}^{-1}$ there is the $\mathrm{CH}_{2}$ asymmetric stretching, at $1711 \mathrm{~cm}^{-1}$ the $\mathrm{C}=\mathrm{O}$ band and at $1648 \mathrm{~cm}^{-1}$ the $\mathrm{C}=\mathrm{C}$ stretching $[12,19,40,42]$ related to oxidized structures and chain terminations. After the artificial ageing the infrared spectra of the untreated rubber sample did not show any significant change: the rubbery tubes were quite old and already very degraded before the beginning of our examination, as confirmed by the low absorption of the $\mathrm{C}=\mathrm{C}-\mathrm{H}$ group at $834 \mathrm{~cm}^{-1}$ (Figure 2a), which is an indicator polyisoprene degradation [12] and by the presence of the complex broad band around $1700 \mathrm{~cm}^{-1}$.

Figure $2 \mathrm{~b}$ shows the infrared spectrum of the EVA 4260 ethylene-vinyl acetate copolymer, which is identical to that of the other copolymer, EVA 4055. At 2915 and $2848 \mathrm{~cm}^{-1}$ are evident the symmetric and asymmetric stretching of $\mathrm{CH}_{2}$, the $\mathrm{C}=\mathrm{O}$ ester signal is at $1740 \mathrm{~cm}^{-1}$ and at 1470 and $1370 \mathrm{~cm}^{-1}$ are seen the $\mathrm{C}-\mathrm{H}$ signals (asymmetric in plane and symmetric in plane). At $1239 \mathrm{~cm}^{-1}$ there is the $\mathrm{C}-\mathrm{C}(\mathrm{O})-\mathrm{O}$ signal, the $-\mathrm{O}-\mathrm{C}$ - band is at $1020 \mathrm{~cm}^{-1}$ and the $\mathrm{C}-\mathrm{H}\left(-\mathrm{CH}_{2^{-}}\right)$at $720 \mathrm{~cm}^{-1}$.

Figure 2c shows the infrared spectrum of the ethylene-butylacrylate copolymer, either EBA40 or EBA320. At 2920 and $2853 \mathrm{~cm}^{-1}$ there are the symmetric and asymmetric stretchings of $\mathrm{CH}_{2}$, the $\mathrm{C}=\mathrm{O}$ ester signal is at $1732 \mathrm{~cm}^{-1}, \delta$ in plane $\mathrm{CH}_{2}$ - polymer backbone at $1460 \mathrm{~cm}^{-1}, \delta$ symmetric in plane $-\mathrm{CH}_{3} \mathrm{n}$-butyl group at $1368 \mathrm{~cm}^{-1}$, the $\mathrm{C}-\mathrm{C}(\mathrm{O})-\mathrm{O}$ signal at $1242 \mathrm{~cm}^{-1}$, the $-\mathrm{O}-\mathrm{C}$ - band at $1160 \mathrm{~cm}^{-1}$, the $\delta$ out of plane $\mathrm{C}-\mathrm{H}$ n-butyl group at $1066 \mathrm{~cm}^{-1}$, the C-C polymer main chain signal at $1021 \mathrm{~cm}^{-1}$ and the $\mathrm{C}-\mathrm{H}\left(-\mathrm{CH}_{2}^{-}\right)$signal at $724 \mathrm{~cm}^{-1}[15]$.

In figure $2 \mathrm{~d}$ it is represented the infrared spectrum of the DLU sample. At $3341 \mathrm{~cm}^{-1}$ there is the signal of the $\mathrm{N}-\mathrm{H}$ stretching, between 2937 and $2861 \mathrm{~cm}^{-1}$ there are the $\mathrm{C}-\mathrm{H}$ asymmetric and symmetric stretching and at $1740 \mathrm{~cm}^{-1}$ the 
signal due to the carbonyl groups in urethane bonds $(\mathrm{C}=\mathrm{O})$. The DLU is a polycarbonateester-polyether polyurethane dispersion and the FTIR spectra presents the characteristic absorption bands of both polyesters (-C(O)-O-C) at $1250 \mathrm{~cm}^{-}$ ${ }^{1}$ and polyethers (-C-O-C-) at $1110 \mathrm{~cm}^{-1}$. The $1641 \mathrm{~cm}^{-1}$ band is assigned to carbonyl groups in urea bond (O-C(O)-NH) while the $1550 \mathrm{~cm}^{-1}$ band is that of a secondary amide (RCONHR') [43, 44].

\section{Monitoring degradation with ATR-FTIR}

The degradation of the five selected conservation treatments (EVA4260, EVA4055, EBA40, EBA320 and DLU) applied on rubber samples was monitored through the ATR-FTIR analysis in order to investigate their stability both to light exposure and when employed for the restoration of polyisoprene objects. Moreover, a sample of untreated rubber was also monitored in order to take into account the possible degradation of rubber under the light exposure. The samples treated with the two ethylene-vinylacetate copolymers showed the typical signals related to the beginning of the oxidation process: the raising of a new band at $1176 \mathrm{~cm}^{-1}$ may be assigned to the C-O-O asymmetric stretching of the peroxidic structures, the broadening of the carbonyl band is related to the formation of acid/ketone/aldehyde structures, while the increasing of signals around $1650 \mathrm{~cm}^{-1}$ is due to new double bonds formed as consequence of the EVA chain breaking and the absorptions around $1780 \mathrm{~cm}^{-1}$ indicate the formation of lactones [45]. The oxidation in the sample treated with EVA4260 is visible after 330 hours of light ageing (Figure 3) while in the sample treated with EVA4055 it appears a little earlier (227 h) (Figure 3 and 4). Although the vinyl acetate (VA) content is said to have some influence on the photo-oxidative stability of EVA copolymers [46], the two copolymers here investigated show a very similar ageing behavior due to their relatively high VA content and the chemical compositions not much different. The decay pattern of the two EBA copolymers is very similar and moreover very close to the one observed for the EVA (figures 5 and 6). There is a clear broadening of the carbonyl band (fig. 5) due to the formation of oxidated structure such as acids, ketones and aldehydes. The peak growing at $1653 \mathrm{~cm}^{-1}$ indicates the presence of new unsatured chain ends. Common to the photooxidation of all types of aliphatic polymers, also in these samples the signal at $1780 \mathrm{~cm}^{-1}$ is due to the formation of lactones [50,51].

The DLU on the treated rubber resulted the less stable under light exposure: the infrared spectra showed the typical degradation of polyurethanes [43, 48, 49]. After 155 hours of ageing the oxidation started to be visible with the peak at $1170 \mathrm{~cm}^{-1}$; after 400 hours there is a strong decrease of the polyether peak at $1100 \mathrm{~cm}^{-1}$ and the disappearance of the peaks of the $\mathrm{CH}_{2}$ vibration and of the carbonyl group at $1365 \mathrm{~cm}^{-1}$ and $1645 \mathrm{~cm}^{-1}$ respectively.

Table 2 resumes the results of the degradation monitoring through ATR-FTIR. The conservation treatment performed with EBA40 resulted the best one: only after 330 hours of light exposure the infrared spectra showed a significant evidence of oxidative processes and chain breaking. On the other hand, the chemical changes observed in the rubber samples treated with the EVA copolymers were similar and their time evolution does not seem much different. From that point of view we can consider equally usable these two types of consolidants, while the polyurethane one is rated as unsuitable.

\section{Monitoring degradation with LED Multispectral Imaging}

The LED Multispectral Imaging measurements on the same rubber samples treated with the different consolidants and light-aged were used to monitor changes in a different spectral range with an information not directly connected to the functional groups of the molecules but possibly capable of revealing hidden contributions to the degradation processes. The result of the monitoring of the artificial degradation of the samples with LED multispectral imaging (LED-MSI) is a control chart constituted by an image where each pixel represents a position point of the rubber surface treated with 
the selected conservation treatment. The pixels are pseudo-colored according to whether they represent a changed or an unchanged area. In this research paper red pixels are the changed pixels of the sample and green pixels correspond to unchanged regions. The first principal component accounts for the information of all the eight wavelengths: all the channels showed a large positive loading weight on this PC.

Figure 8 (left) shows the color images of the monitored rubber samples treated with EVA4260 (a), EVA4055 (b), EBA40 (c), EBA320 (d) and DLU (e) and the respective control charts of the sample area delimited by the blue rectangle for the samples aged for 155 (center) and 400 hours (right). Red pixels in the charts indicate the region of the sample that could be considered statistically changed with a significance higher than $99 \%$. In this area the reflectance of the surface changed under the effect of the photo-oxidative degradation caused by the light exposure of the samples. The more are the red pixels the more the surface of the sample is degraded. The control chart of the untreated rubber sample did not show any changed pixels, so we can exclude that the degraded areas in treated samples were caused by the degradation of the rubber: therefore each variation identified in the treated samples can be considered caused by the consolidant material used or by its interaction with the rubber support. Moreover, the wavelengths responsible for the out of control were mainly the UV and the IR, even if small changes were detected also in the visible range. Looking at the number of changed pixels in the control charts of the five treated samples we can state that the rubber sample treated with EVA4260 resulted the least changed for the LED-MSI monitoring.

In figure 9 are represented the reflectance spectra of altered (up) and non-altered (down) pixels for the sample treated with EVA4260. The reflectance spectra of the out of control pixel before and after the ageing are pretty different: the spectrum of the aged sample is statistically changed respect with the unaged one. While the reflectance spectra of an in control pixel is not statistically different as shown in the lower image in figure 9.

\section{Mechanical degradation}

The average breaking times for the rubber samples both treated with the consolidants and untreated were determined in order to understand the effect of the treatments on the rubber and to evaluate the selected materials. The average breaking times for the ethylene-vinyl acetate copolymers EVA4260 and EVA4055 were respectively $206 \pm 5$ and $192 \pm 7$ hours while for the ethylene-butyl acrylate copolymers EBA40 and EBA320 the breaking times were lower, $120 \pm 7$ and $91 \pm 9$ hours. The sample treated with the polyurethane (DLU) showed the best mechanical strength because after 240 hours the rubber was still intact. The average breaking time of the untreated rubber sample was $125 \pm 9$ hours: the ethylene-butyl acrylate copolymers worsen the behavior of the rubber material in terms of elasticity and tensile strength while the ethylene-vinyl acetate copolymers increased it. Moreover the vinyl acetate (VA) content slightly influenced the tensile strength: the EVA 4260 sample, which has a higher VA content, showed a longer mechanical resistance than the EVA4055.

\section{Final selection}

The LED-MSI method measured in a quantitative and reliable manner the reflectance variation of the sample surface: the spectral range of the reflectance ranges from ultraviolet to near infrared, including the visible range. The PCA and Shewhart Control charts were used to elaborate the reflectance information in order to get a sensitive, robust and reliable tool that was able to identify spectral variation not visible by human eyes. The materials that is analyzed does not affect the results of the method because before the analysis the LED exposure time and the camera parameters are always optimized in order to get a good (reflected) image and in consequence a good spectra for each type of material. The method can easily detect chromatic changes: in the restoration and conservation of cultural heritage is very 
important to ensure the chromatic stability of the restored artwork. In this work, the LED-MSI method allowed the assessment of the chromatic stability of different consolidants applied on rubber, giving a way to measuring their final (chromatic) effects on the material.

The final choice of consolidant was supported by the combination of the results obtained from the ATR-FT-IR spectroscopic analysis, the MSI monitoring and the mechanical tests.

The light degradation was performed at controlled temperature in order to avoid the thermal effects. Moreover, the rubber materials used for the artificial degradation came from the real artwork: in consequence they were strongly representative of the restoration needs.

The good overall response of the EVA4260 copolymer under light ageing was supported by the positive results obtained in the consolidation of rubber specimens and in the time monitoring of the mechanical properties after the application, thus allowing the restorers to consider the EVA4260 as the most suitable consolidant among those tested in this study. Consequently, the polymer has been employed for the complete restoration of the artwork "Presagi di Birnam" by Carol Rama prior to an exhibition of the works of the Artist at Museu d'Art Contemporani de Barcelona, on November 2014 [53]. An example of the visible effects of the consolidation treatment with the EVA copolymer is shown in Fig. 10. In addition to the materiality reintegration the treatment produced an appreciable recovery of the rubbery touch and flexibility in the inner tubes of the artwork.

\section{Conclusions}

The aim of this work was the identification of the best consolidation treatment for rubber artworks in order to ensure its long-term protection and security. The objective was achieved by selecting and testing five different consolidating products (EVA4260, EVA4055, EBA40, EBA320 and DLU) by means of accelerated photo-degradation that were monitored over time through infrared spectroscopy, for the identification of chemical-physical changes, and by LED multispectral imaging coupled to statistics to assess reflectance variations and by the evaluation of the mechanical stress. The degradation was performed under controlled temperature at no more than $35^{\circ} \mathrm{C}$ in order to exclude the effect of thermal degradation that could affect the ageing of polymers, especially because the materials studied in this work have low melting temperatures.

The EVA4260 consolidant showed the less changes under the LED-MSI, and together with the other results of this comprehensive study carried out in a quantitative manner, it resulted the best product for the required rubber consolidation. Moreover, the EVA4260 consolidant had a good response to the mechanical stress (resulted the second choice after the DLU which anyway is unsuitable according to the spectroscopic analysis) and the first changed observed with ATR-FT-IR appears after 330 hours (better than the EVA4055, DLU and EBA320) showing a response to the degradation very similar to the EBA40.

Although the substitution of the damaged material [12] is often preferred to the restoration of rubber artworks, we showed and demonstrated that the recovery of the original materials is possible. Moreover, we also highlighted that there are many commercial products already used in other fields that, if well studied and tested with simulated degradation, may be employed for the conservation and restoration of cultural heritage objects. Furthermore, the LED imaging technique may become a new standard method for the comparison and assessment of new conservation materials and treatments.

\section{Acknowledgments}


The research was supported by TOTH Associazione per la ricerca scientifica ONLUS. The Authors would like to thank the Museo del Novecento di Milano and SRA Instruments (Cernusco sul Naviglio (MI), Italy) for the analysis using the Agilent 4100 Exoscan FTIR portable spectrometer.

\section{Compliance with ethical standards}

Conflict of interest: The authors declare that they have no competing interest

\section{References}

1. Mitchell G, France F, Nordon A, Leung Tang P, Gibson L. Assessment of historical polymers using attenuated total reflectance-Fourier transform infra-red spectroscopy with principal component analysis, Heritage Science 2013; 1:28

2. Schilling M, Bouchard M, Khanjian H, Learner T, Phenix A, Rivenc R. Application Of Chemical And Thermal Analysis Methods For Studying Cellulose Ester Plastics. Accounts Of Chemical Research 888896; June 2010; Vol. 43, No. 6.

3. Cucci C, Bigazzi L, Picollo M. Fibre Optic Reflectance Spectroscopy as a non-invasive tool for investigating plastics degradation in contemporary art collections: A methodological study on an expanded polystyrene artwork. Journal of Cultural Heritage 14. 2013; 290-296.

4. Poli T, Chiantore O, Giovagnoli A, Piccirillo A. FTIR imaging investigation in MIR and in an enlarged MIR-NIR spectral range. Anal Bioanal Chem (2012); 402:2977-2984

5. Miliani C, Rosi F, Brunetti BG, Sgamellotti A. In Situ Non-invasive Study Of Artworks: The Molab Multi-Technique Approach. Accounts Of Chemical Research. June 2010; 728-738; Vol. 43, No. 6.

6. Kehlet C, Del Federico E, Schahbaz H, Catalano A, Dittmer J, Nielsen NC. Non-invasive characterization of polymeric materials in relation to art conservation using unilateral NMR combined with multivariate data analysis. Anal. Methods 2013; 5, 4480-4486.

7. Chiantore O, Ploeger R, Poli T, Ferriani B. Materials and techniques in the pictorial oeuvre of Lucio Fontana. Studies in Conservation. 2012; 57 (2), pp. 92-105.

8. Ploeger R, René De La Rie E, McGlinchey CW, Palmer M, Maines CA, Chiantore O. The long-term stability of a popular heat-seal adhesive for the conservation of painted cultural objects. Polymer Degradation and Stability. 2014;107, pp. 307-313.

9. Bianco L, Avalle M, Scattina A, Croveri P, Pagliero C, Chiantore O. A study on reversibility of BEVA ${ }^{\circledR} 371$ in the lining of paintings. Journal of Cultural Heritage. 2015; Vol. 16, Issue 4, pp. 479-485.

10. Nuttgens F, Tinker Z. The conservation of rubberised textiles: Two case histories. The Conservator. 2000; 24:1, 24-38.

11. Calia A, Colangiuli D, Lettieri M, Matera L. A deep knowledge of the behaviour of multi-component products for stone protection by an integrated analysis approach. Progress in Organic Coatings. May 2013; Vol.76, Issue 5, pp. 893-899.

12. Weerdenburg S, Van Oosten T, De Groot S, Coelewij L. The conservation of an early assemblage by Richard Serra: A rubber issue. ICOM-CC, Modern materials and contemporary arts. Proceeding of $17^{\text {th }}$ Triennial Conference, 2014 Melbourne.

13. Forrest MJ. Chemical analysis of rubber samples that had been naturally aged for 40 years. Polymer Testing 20; 2001, 151-158.

14. Linos A, Berekaa MM, Reichelt R, Keller U, Schmitt J, Flemming H, Kroppenstedt RM, Steinbuchel A. Biodegradation Of Cis-1,4-Polyisoprene Rubbers By Distinct Actinomycetes: Microbial Strategies And Detailed Surface Analysis. Applied and Environmental Microbiology; Apr. 2000, Vol. 66, No. 4, pp. 1639-1645.

15. Chércoles Asensio R, San Andrés Moya M, De la Roja JM, Gomez M. Analytical characterization of polymers used in conservation and restoration by ATR-FTIR spectroscopy. Anal Bioanal Chem; 2009 395: 2081-2096.

16. Llamas R, Talamantes MC. An analytical study of polypropylene as a support for paint layers. From concept to material in contemporary art. Journal of Cultural Heritage. March-April 2014; Vol. 15, Issue 2, pp. 136-143. 
17. Lazzari M, Ledo-Suárez A, López T, Scalarone D, López-Quintela MA. Plastic matters: an analytical procedure to evaluate the degradability of contemporary works of art. Anal Bioanal Chem. 2011; 399:2939-2948.

18. Pintus V, Ploeger R, Chiantore O, Wei S, Schreiner M. Thermal analysis of the interaction of inorganic pigments with $\mathrm{p}(n \mathrm{BA} / \mathrm{MMA})$ acrylic emulsion before and after UV ageing. Journal of Thermal Analysis and Calorimetry. 2013, Vol. 114, Issue 1, pp. 33-43.

19. Ploeger R, René de la Rie E, McGlinchey CW, Palmer M, Maines CA, Chiantore O. The long-term stability of a popular heat-seal adhesive for the conservation of painted cultural objects. Polymer Degradation and Stability. 2014; Vol. 107, pp. 307-313.

20. Marengo E, Manfredi M, Zerbinati O, Robotti E, Mazzucco E, Gosetti F, Bearman G, France F, Shor P. Technique based on LED multispectral imaging and multivariate analysis for monitoring the conservation state of the dead sea scrolls. Analytical Chemistry. 2011; 83(17), pp. 6609-6618.

21. Marengo E, Manfredi M, Zerbinati O, Robotti E, Mazzucco E, Gosetti F, Bearman G, France F, Shor P. Development of a technique based on multi-spectral imaging for monitoring the conservation of cultural heritage objects. Analytica Chimica Acta. 2011; 706(2), pp. 229- 237.

22. Manfredi M, Bearman G, France F, Shor P, Marengo E. Quantitative Multispectral Imaging For The Detection Of Parchment Ageing Caused By Light: A Comparison With ATR-FTIR, GC-MS And TGA Analyses. Int J Conserv Sci. Jan-Mar 2015; 6(1), pp. 3-14.

23. Loadman MJR. Rubber: Its History, Composition and Prospects for Conservation. In "Saving the Twentieth Centrury: The Conservation of Modern Materials". Canadian Conservation Institute. Symposium '91, 15-20 September 1991, Ottawa. Ed. David W. Grattan; 1993, pp. 59-74.

24. Duboisset, F. Modernisme américain: un fauteuil MMA de George Nelson, 1958. Etude, consolidation et protection de caoutchouc naturel - Mémoire de diplome de restaurateur du patrimoine, spécialité: mobilier, Institut National du patrimoine, 2010.

25. Duboisset F. American Modernism, a MMA chair by George Nelson (1958). Technical study, consolidation and protection of natural rubber. Proceeding of Future Talks Conference 2011, Munich. Future Talks 011. Technology and Conservation of Modern Materials in Design. Ed. Tim Bechtold, 2011, pp.74-79, ISBN 978-3-9813755-5-8.

26. Berger GA. Unconventional treatments for unconventional paintings. Studies in Conservation. 1976; 21, pp. $115-128$.

27. Berger GA. Consolidation for delaminating paintings. Preprints to the ICOM meeting, Zagreb. 1978; pp. $1-19$.

28. Berger GA. More unconventional treatments for unconventional art. Studies in Conservation. 1990; 35, pp. 1-14.

29. Rossi Doria M. Il consolidamento strutturale dei dipinti su tela secondo Gustav Berger. Valutazioni e riflessioni a trent'anni dall'introduzione del BEVA 371. Progetto Restauro. 2005; 33, pp. 2-7.

30. Ackroyd, P. The structural conservation of canvas paintings: changes in attitude and practice since the early 1970s. Reviews in Conservation. 2002; vol. 3, pp. 3-14.

31. Caley T. A note on the reversal of Beva linings. Pict Restor. 1998; 14:13.

32. Down JL, MacDonald MA, Tetreault J, Williams RS. Adhesive testing at the Canadian Conservation Institute: an evaluation of selected poly(vinyl acetate) and acrylic adhesives. Stud Conserv. 1996; 41(1): $19-44$.

33. Apollonia L, Pinna D, Cauzzi D, Casoli A, Campani E, Berzioli M, et al. Atti del congresso colore e conservazione: L'attenzione alle superfici pittoriche: Materiali e metodi per il consolidamento e metodi scientifici per valutarne l'efficacia. 2008; 2, pp. 9-32.

34. Shore SK. In: Loss compensation symposium poster-prints, Western Association for Art Conservation Annual Meeting 1993: 1994, pp. 19-23.

35. Benjamin R. The separation of two fabrics bonded together with Beva371. Pict Restor. 1994; 5: 5-7.

36. Jais-Camin C. Etude su la reversibilite d'une nouvelle method de doublage avec la Beva 371 vaporisee chaude. Conserv Restaur Des Biens Cult. 1997; 10:47-53.

37. Malpass DB. Introduction to Industrial Polyethylene: Properties, Catalysts, and Processes. Ed. John Wiley \& Sons; 2010, ISBN: 978-0-470-62598-9.

38. Ehrenstein GW. Polymeric Materials: Structure, Properties, Applications, Hanser Publishers; 2001.

39. Down JL, MacDonald MA, Tetreault J, Williams RS. Adhesive testing at the Canadian Conservation Institute - An evaluation of selected poly(vinylacetate) and acrylic adhesives. Studies in Conservation. 1996; 41, pp.19-44.

40. De La Orden MU, Montes JM, Urreaga JM, Bento A, Ribeiro MR, Perez E, Cerrada ML. Thermo and photo-oxidation of functionalized metallocene high density polyethylene: effect of hydrophilic groups. Polymer Degradation and Stability. 2015; 111, 78-88.

41. Rasband, WS, ImageJ, U. S. National Institutes of Health, Bethesda, Maryland, USA, http://imagej.nih.gov/ij/, 1997-2014. 
42. Nor HM, Ebdon JR. Ozonolysis of natural rubber in chloroform solutions. Part 1. A study by GPC and FTIR spectroscopy. Polymer. 2000; 41, 2359-2365.

43. Van Oosten T. PUR Facts, Conservation of polyurethane foam in art and design. Amsterdan University Press; 2011, ISBN-10: 9089642102.

44. Ayres E, Vasconcelos WL, Orèfice RL. Attachment of Inorganic Moieties Onto Aliphatic Polyurethanes. Materials Research. 2007; Vol. 10, No. 2, 119-125.

45. Jing J, Shuanhjun C, Jun Z. UV aging behavior of ethylene-vinyl acetate copolymers (EVA) with different vinyl acetate contents. Polymer Degradation and Stability; 2010, 95:725-732.

46. Scaffaro R, Botta L, Gallo G. Photo-oxidative degradation of poly(ethylene-co-vynil acetate)/nisin antimicrobial films. Polymer Degradation and Stability. 2012; 97:653-660.

47. Mishra A, Seethamraju K, Delaney J, Willoughby P, Faust R. Long-term in vitro hydrolytic stability of thermoplastic polyurethanes. J Biomed Mater Res-Part A. 2015; 103(12), pp. 37983806.

48. Merlatti C, Perrin FX, Aragon E, Margaillan A. Natural and artificial weathering characteristics of stabilized acrylic-urethane paints. Polymer Degradation and Stability. 2008; 93:896-903.

49. Zhang Y, Maxted J, Barber A, Lowe C, Smith R. The durability of clear polyurethane coil coatings studied by FTIR peak fitting. Polymer Degradation and Stability. 2013; 98:527-534.

50. Allen NS, Edge M, Rodriguez M, Liauw CM, Fontan E. Aspect of the thermal oxidation of ethylene vinyl acetate copolymer. Polymer Degradation and Stability. 2000; 68 (3), pp. 363-371.

51. Tidjani A, Arnaud R. Photo-oxidation of linear low density polyethylene: A comparison of photoproducts formation under natural and accelerated exposure. Polymer Degradation and Stability. 1993; 39 (3), 285292.

52. Chiantore O, Lazzari M. Photo-oxidative stability of paraloid acrylic protective polymers. Polymer. 2001; 42 (1), 17-27.

53. Dressen A, Grandas T, Preciado B. The Passion According to Carol Rama. Exhibition catalogue; 2014. Eng.-978-84-92505-73-9.

\section{Figure Captions}

Fig1 Color image of the artwork "Presagi di Birnam" made by the artist Carol Rama.

Fig2 Infrared spectrum of a sample from the artwork "Presagi di Birnam" from Carol Rama (a), of the ethylene vinylacetate copolymer EVA4260 (b), of the ethylene butyl-acrylate copolymer EBA40 (c), and of the DLU sample (d).

Fig3 Infrared spectra of the sample treated with EVA4260 after 31, 155, 227, 330 and 400 hours of ageing in solar box.

Fig4 Infrared spectra of the sample treated with EVA4055 after 31, 155, 227, 330 and 400 hours of ageing in solar box.

Fig5 Infrared spectra of the sample treated with EBA40 after 31, 155, 227, 330 and 400 hours of ageing in solar box.

Fig6 Infrared spectra of the sample treated with EBA320 after 31, 155, 227, 330 and 400 hours of ageing in solar box.

Fig7 Infrared spectra of the sample treated with DLU after 31, 155, 227, 330 and 400 hours of ageing in solar box.

Fig8 Color images (left) of the monitored rubber samples treated with EVA4260 (a), EVA4055 (b), EBA40 (c), EBA320 (d) and DLU (e) and the respectively control charts (of the sample area delimited by the blue rectangle) for the samples aged for 155 (center) and 400 hours (right). Red pixels in the charts indicate the region of the sample that could be considered statistically changed.

Fig9 Reflectance spectra of out of control (up) and incontrol (down) pixels for the sample treated with EVA4260. The reflectance spectra of the aged sample in the of the out of control pixel is statistically changed respect with the unaged one, while the two in control pixel showed very similar reflectance spectra.

Fig10 Color images of the rubber sample before (left) and after (right) the treatment with the best consolidant identified in this study, the EVA4260.

\section{Tables}




\begin{tabular}{|c|c|c|c|}
\hline Name & Composition & Content & Melt index \\
\hline EVA4260 & ethylene-vinyl acetate & Vinyl acetate 41-44\% & $65-85$ \\
\hline EVA4055 & ethylene-vinyl acetate & Vinyl acetate 38-41\% & $48-62$ \\
\hline EBA40 & ethylene-butyl acrylate & Butyl acrylate 33-37\% & $35-45$ \\
\hline EBA320 & ethylene-butyl acrylate & Butyl acrylate 33-37\% & $260-350$ \\
\hline DLU & Aliphatic polycarbonateester-polyether polyurethane & - & $200-230$ \\
\hline
\end{tabular}

Tab 1 Consolidant materials, chemical composition, monomer content and melt index of the selected products.

\begin{tabular}{|c|c|c|c|}
\hline $\begin{array}{c}\text { Conservation } \\
\text { Treatment }\end{array}$ & $\begin{array}{c}\text { Hours of } \\
\text { ageing }\end{array}$ & Wavelengths & Suggested Modifications \\
\hline $\begin{array}{l}\text { EVA4260 } \\
\text { EVA4055 }\end{array}$ & $\begin{array}{l}330 \mathrm{~h} \\
227 \mathrm{~h}\end{array}$ & $\begin{array}{l}\text { new peak at } 1176 \mathrm{~cm}^{-1} \\
\text { new peak at } 1780 \mathrm{~cm}^{-1} \\
\text { broadening of carbonyl band } \\
\text { raising of the band at } 1653 \mathrm{~cm}^{-1}\end{array}$ & $\begin{array}{l}\text { peroxidic structures C-OO } \\
\text { carbonyl lactone } \\
\text { acids, ketone and aldehydes } \\
\text { formation } \\
\text { double bond formation }\end{array}$ \\
\hline $\begin{array}{r}\text { EBA320 } \\
\text { EBA40 }\end{array}$ & $\begin{array}{l}155 \mathrm{~h} \\
330 \mathrm{~h}\end{array}$ & $\begin{array}{l}\text { new peak at } 1176 \mathrm{~cm}^{-1} \\
\text { new peak at } 1780 \mathrm{~cm}^{-1} \\
\text { broadening of carbonyl band } \\
\text { raising of the band at } 1653 \mathrm{~cm}^{-1}\end{array}$ & $\begin{array}{l}\text { peroxidic structures } \mathrm{C}-\mathrm{OO} \\
\text { carbonyl lactone } \\
\text { acids, ketone and aldehydes } \\
\text { formation } \\
\text { double bond formation }\end{array}$ \\
\hline DLU & $155 \mathrm{~h}$ & $\begin{array}{l}\text { decrease of the peak at } 1100 \mathrm{~cm}^{-1} \\
\text { new peak at } 1170 \mathrm{~cm}^{-1} \\
\text { decrease of the peak at } 1365 \mathrm{~cm}^{-1} \\
\text { decrease of the peak at } 1645 \mathrm{~cm}^{-1}\end{array}$ & $\begin{array}{c}\text { polyether (-C-O-C-) } \\
\text { peroxidic structures } \\
\mathrm{CH}_{2} \text { vibration } \\
\text { carbonyl group }(\mathrm{O}-\mathrm{C}(\mathrm{O})-\mathrm{NH})\end{array}$ \\
\hline
\end{tabular}

Tab 2 Consolidant materials, hours of ageing when the spectra showed significant changes, relevant wavelengths, suggested modifications. 


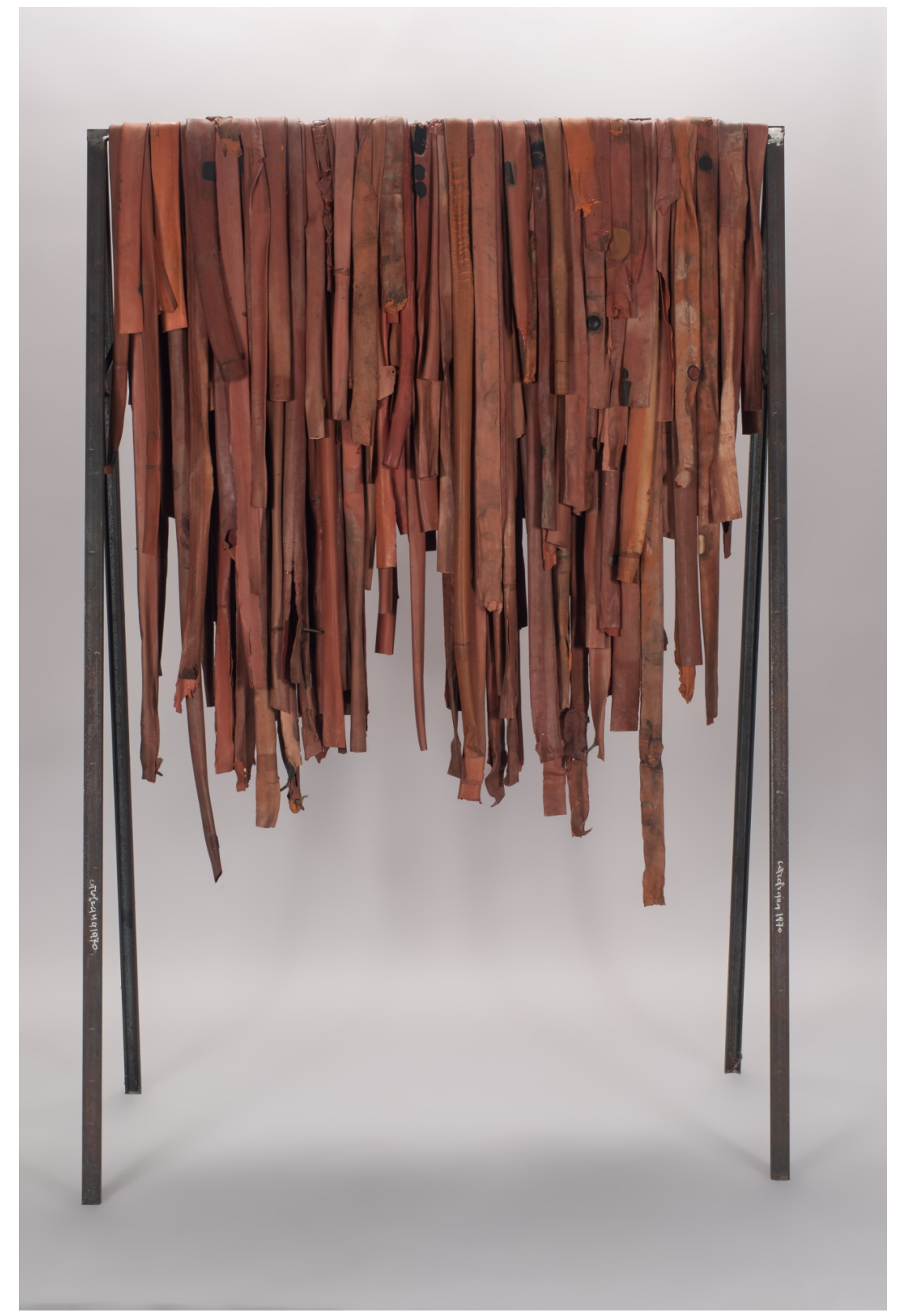

Fig1 


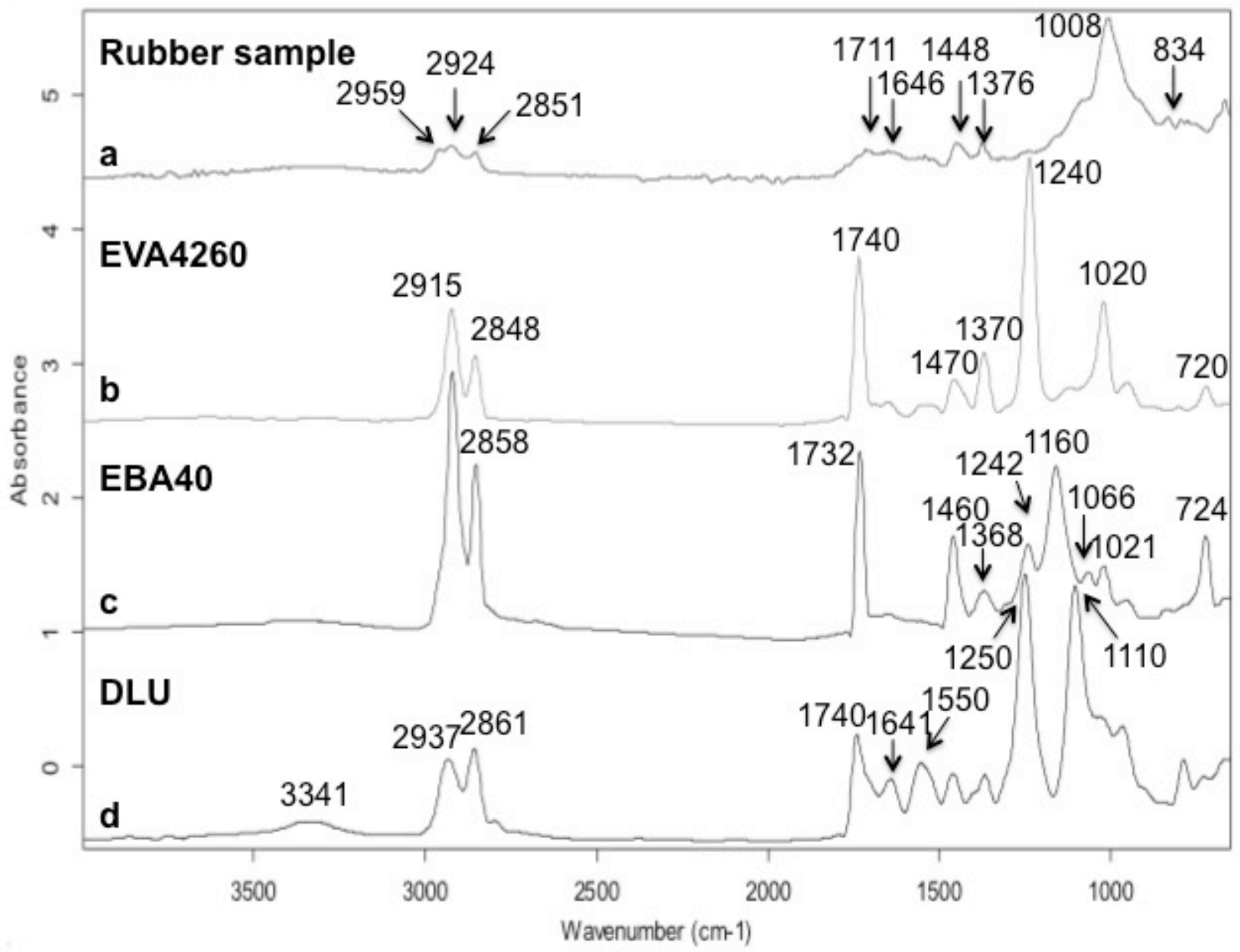

Fig2 


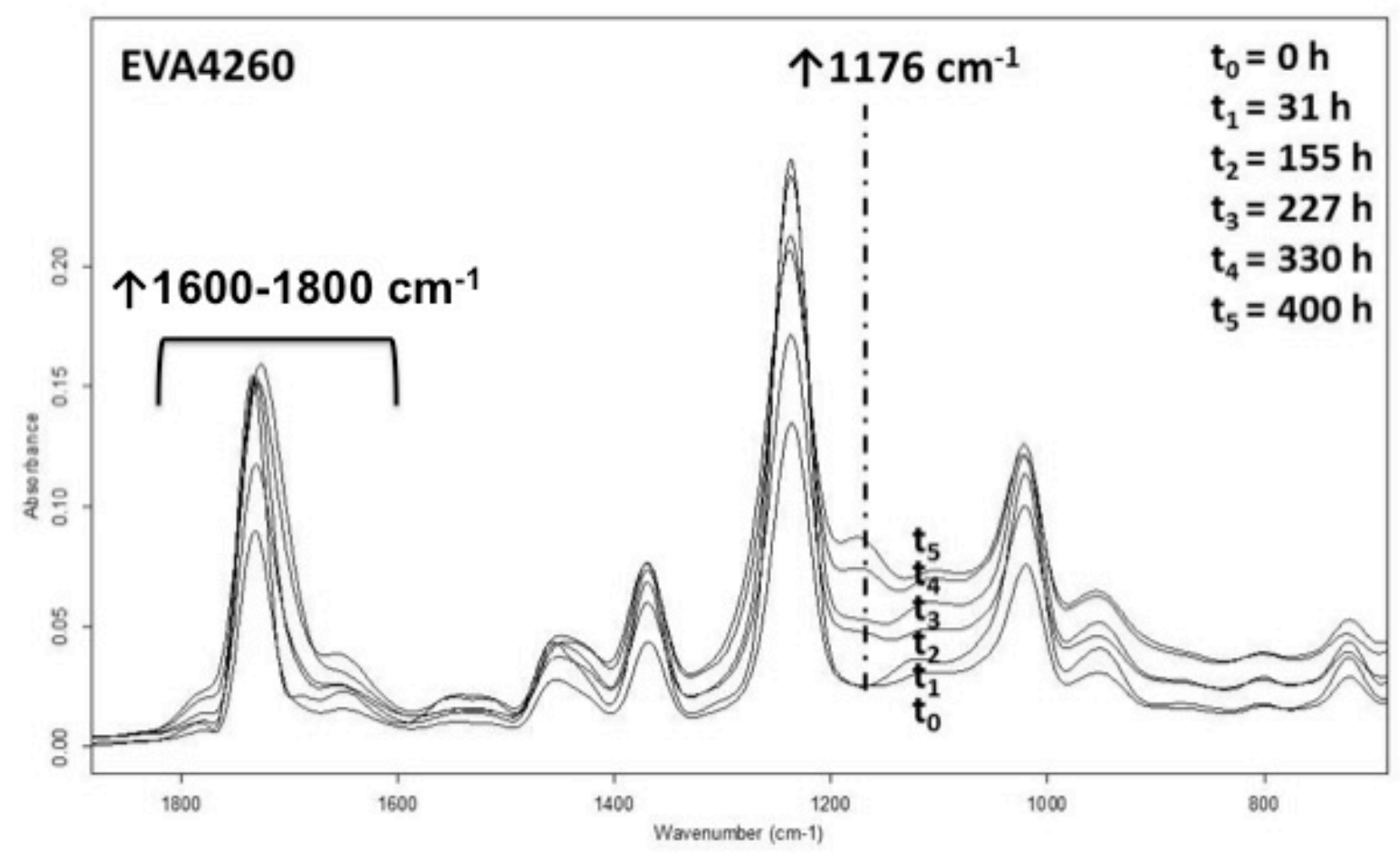

Fig3 


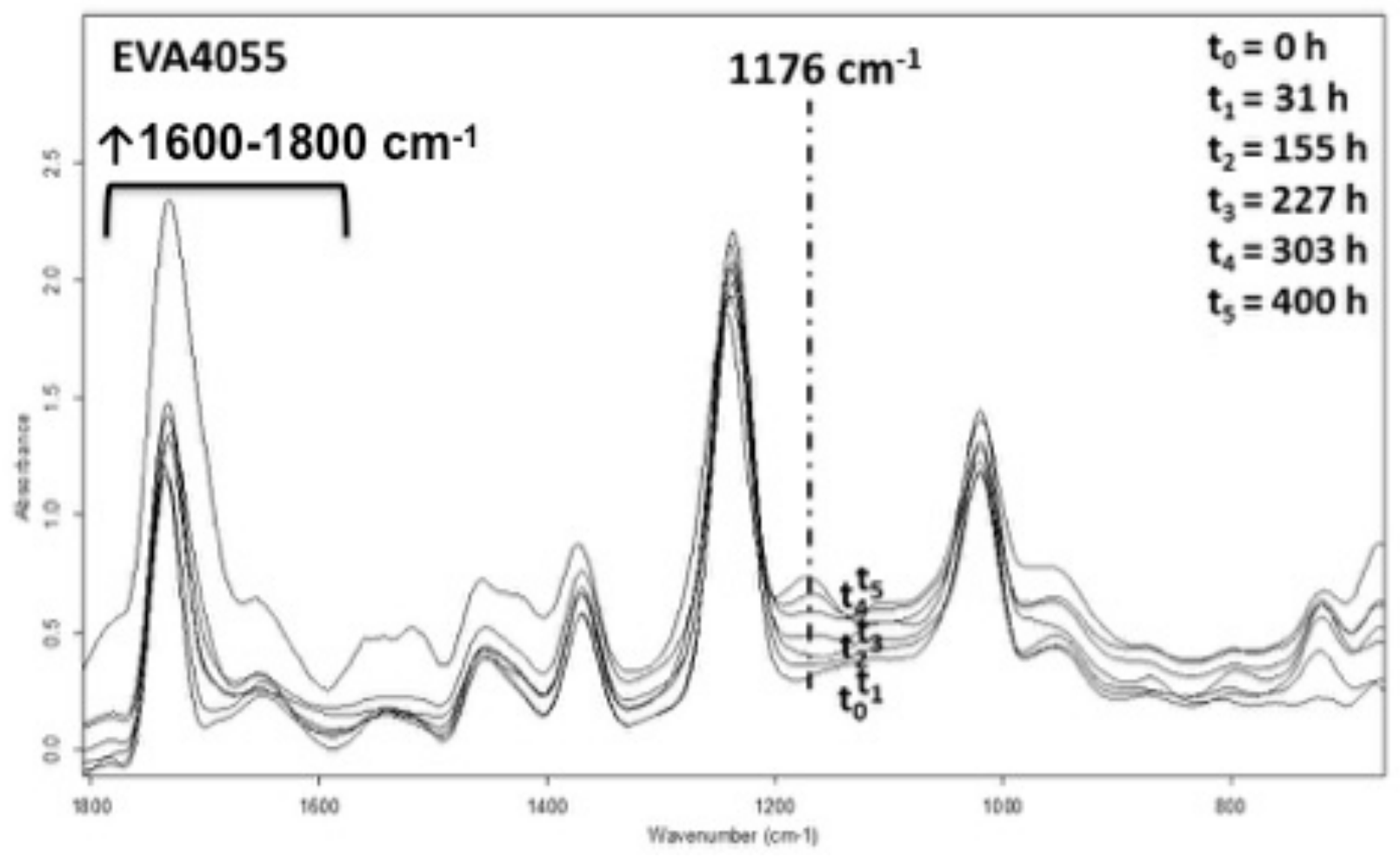

Fig4 


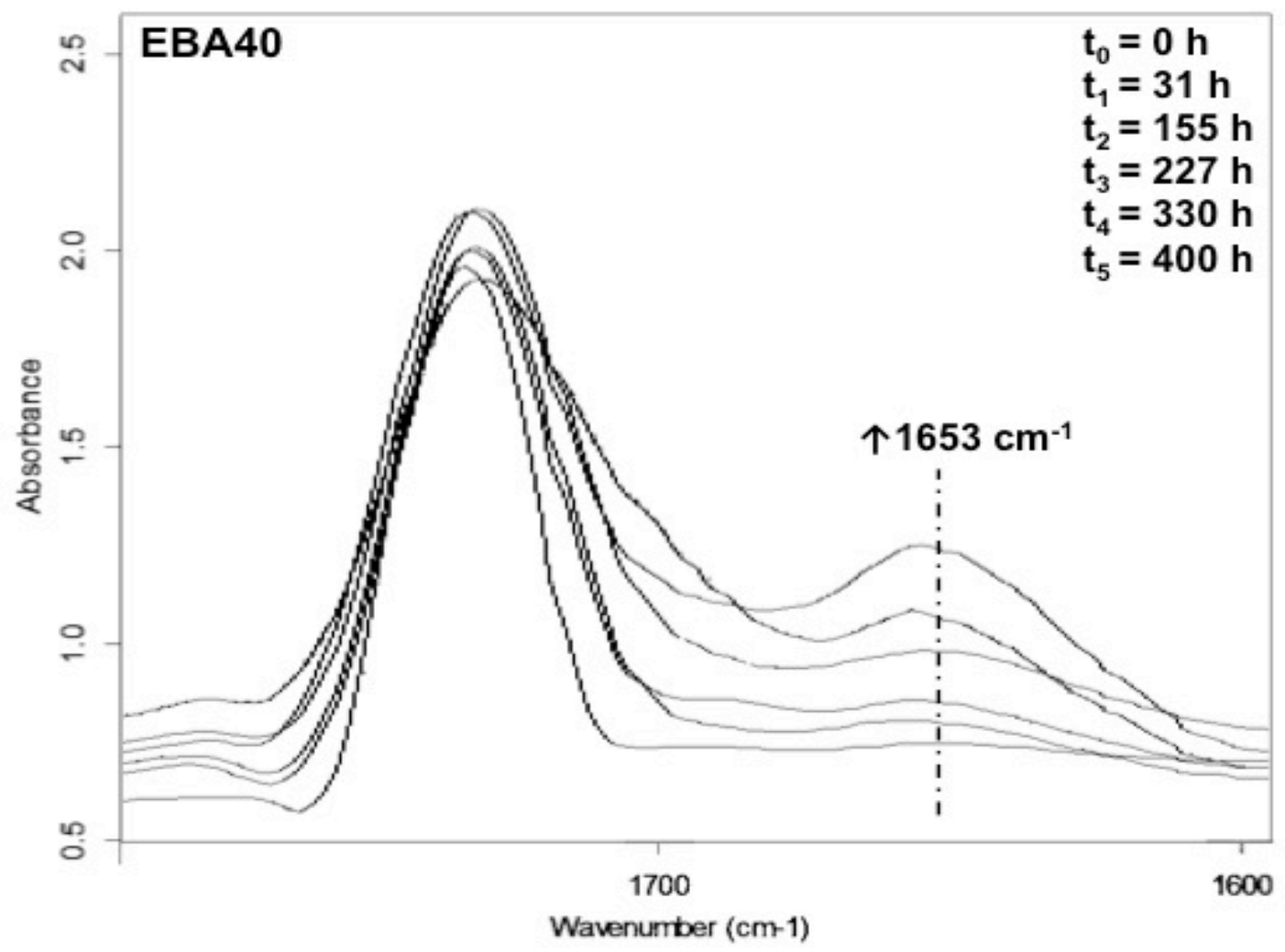

Fig5 


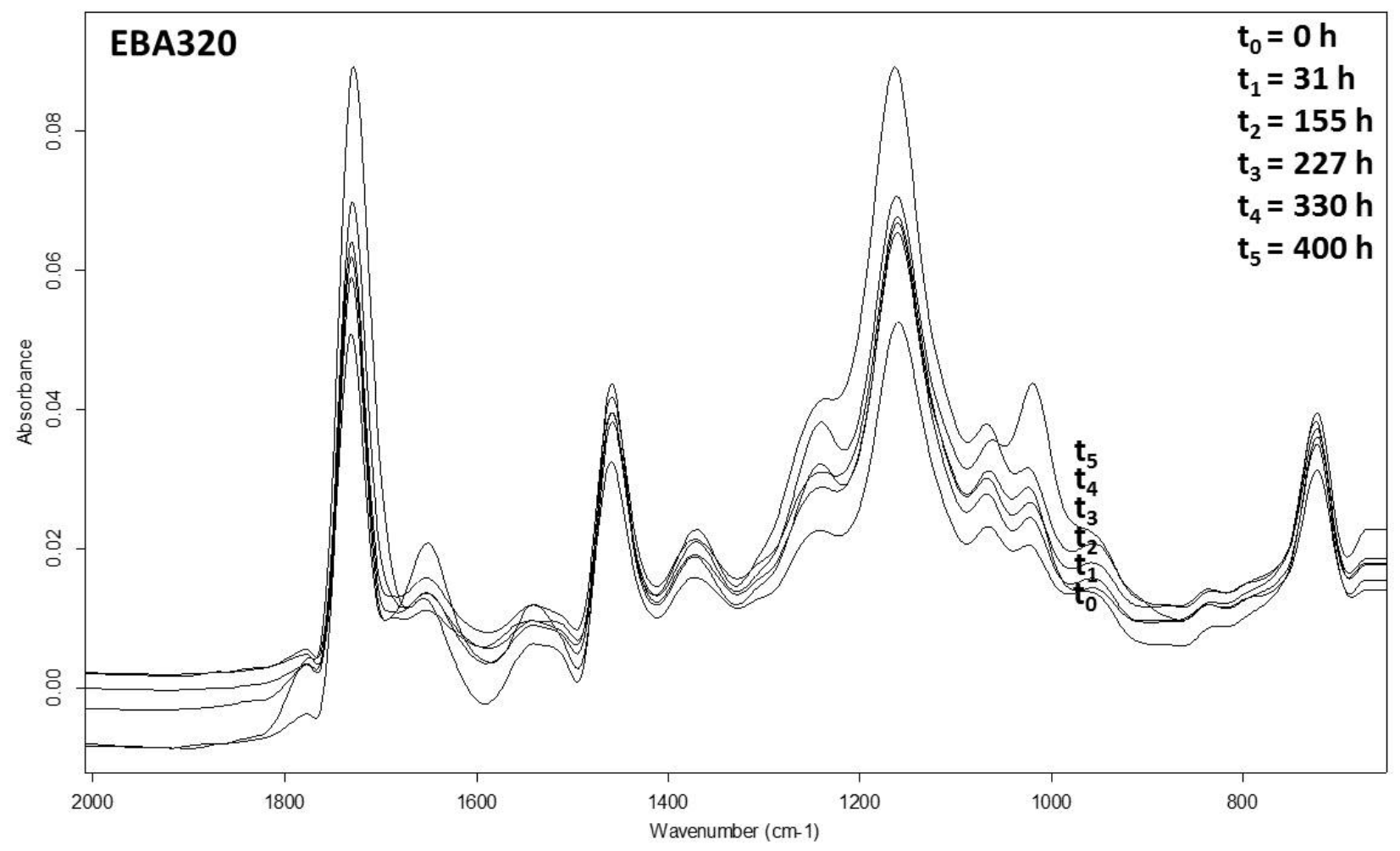

Fig6 


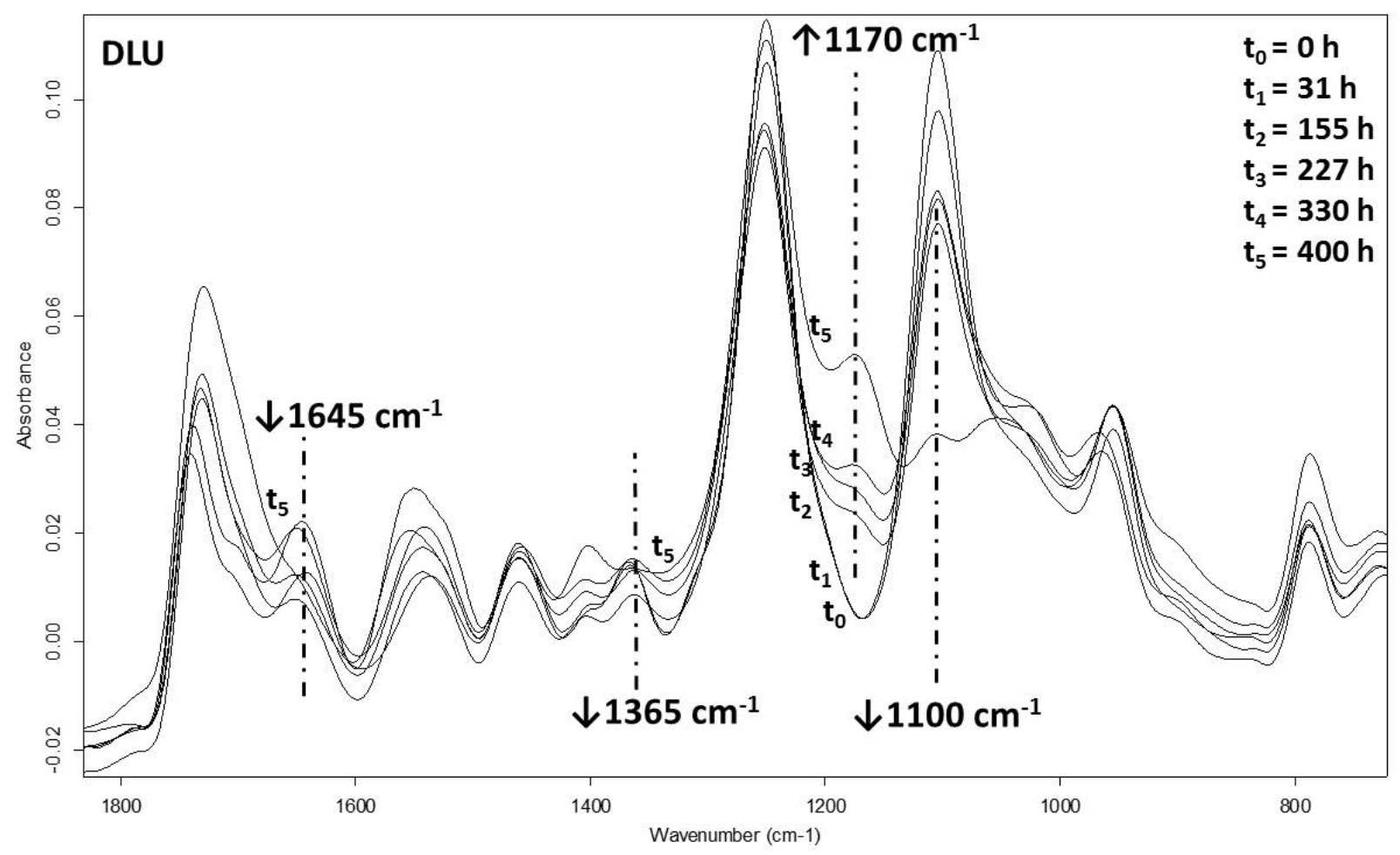

Fig7 
a

Color image - rubber+EVA4260

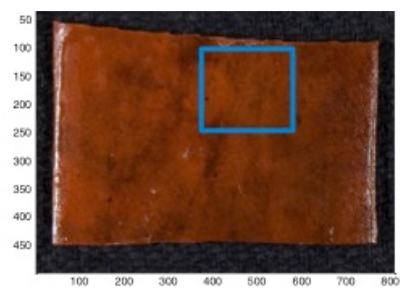

Color image - rubber+EVA4055

b

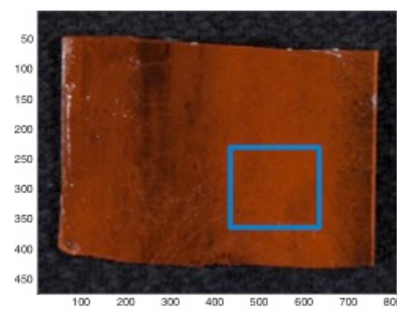

Color image - rubber+EBA40

C

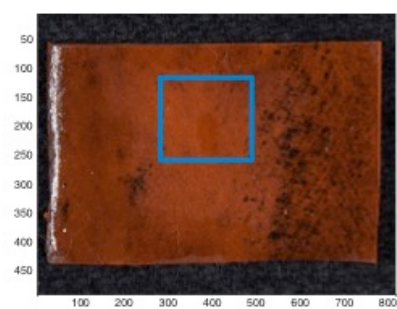

Color image - rubber+EBA320

d

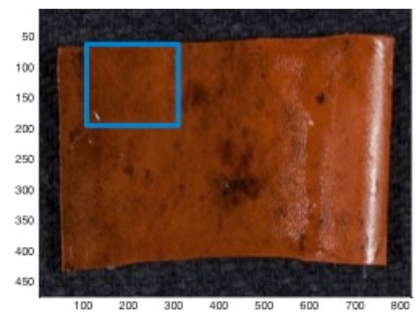

e

Color image - rubber+DLU

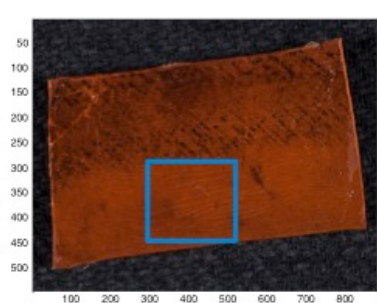

Control chart Monitoring $155 \mathrm{~h}$ aged

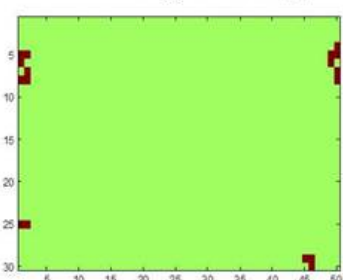

Control chart Monitoring $155 \mathrm{~h}$ aged

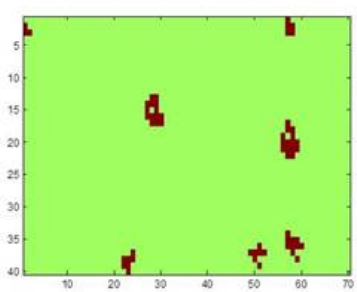

Control chart Monitoring $155 \mathrm{~h}$ aged

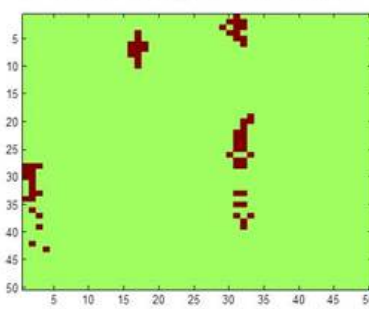

Control chart Monitoring $155 \mathrm{~h}$ aged

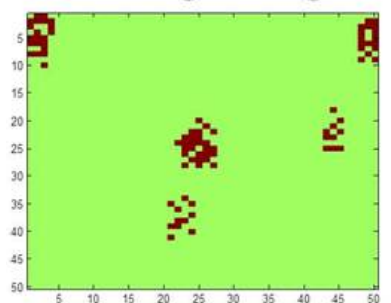

Control chart Monitoring $155 \mathrm{~h}$ aged

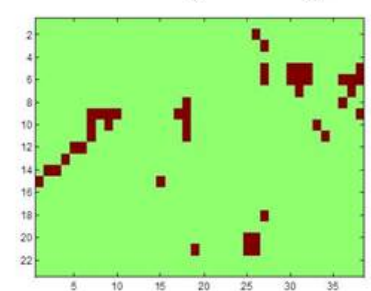

Control chart Monitoring $400 \mathrm{~h}$ aged

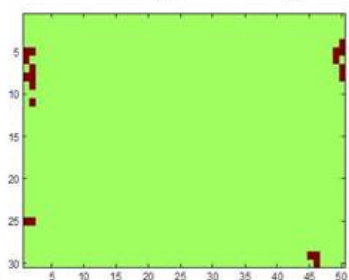

Control chart

Monitoring $400 \mathrm{~h}$ aged

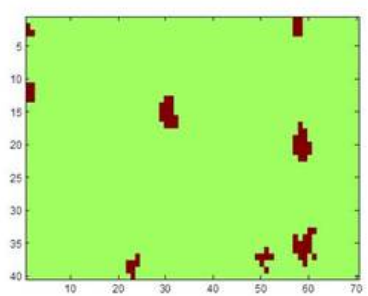

Control chart

Monitoring $400 \mathrm{~h}$ aged

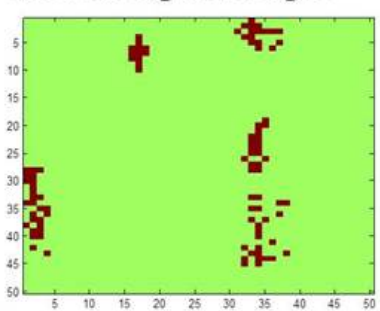

Control chart

Monitoring $400 \mathrm{~h}$ aged

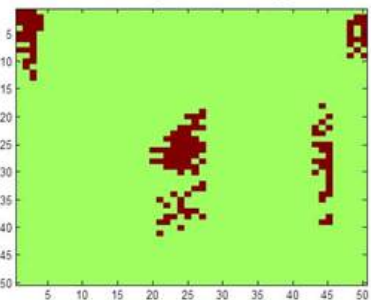

Control chart

Monitoring $400 \mathrm{~h}$ aged

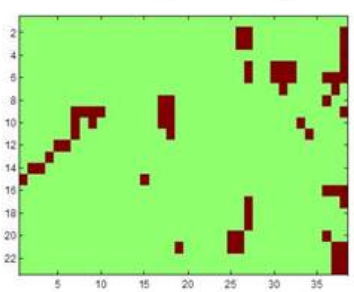

Fig8 

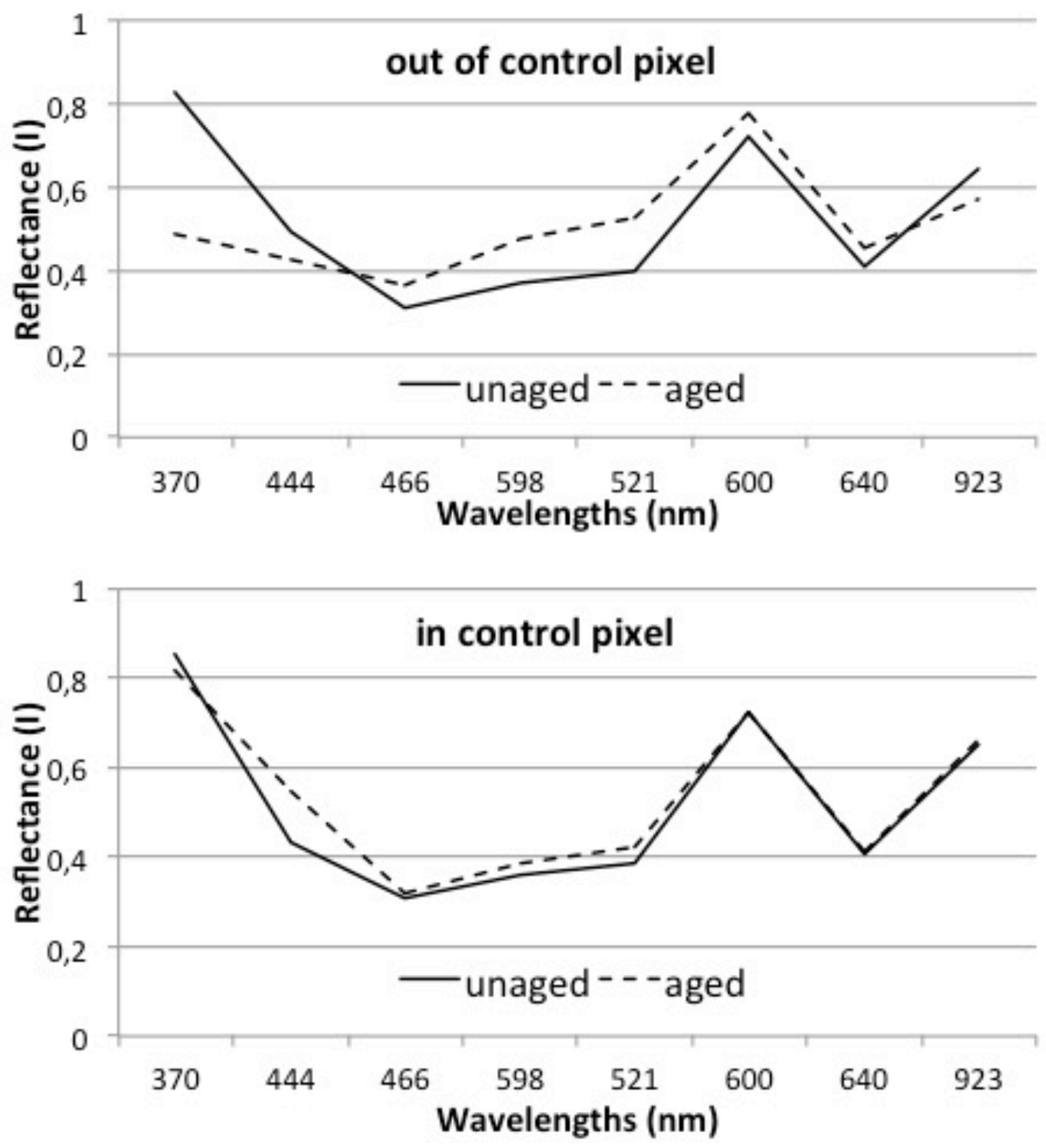

Fig9 


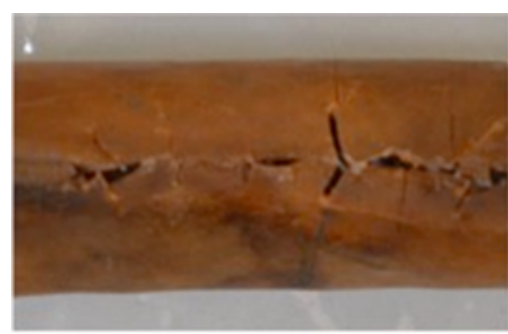

Rubber before the treatment with EVA4260

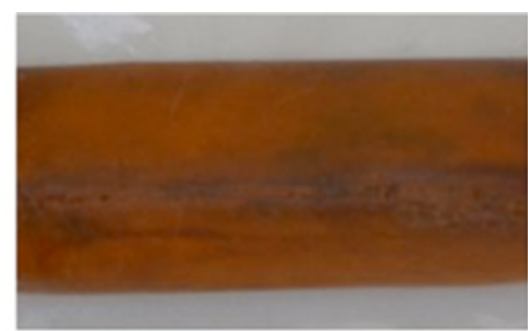

Rubber after the treatment with EVA4260

Fig10 